\title{
Anatomical Relationship of Lingual Nerve to the Region of Mandibular Third Molar
}

\author{
Marcelo Breno Meneses Mendes ${ }^{1}$, Carla Maria de Carvalho Leite Leal Nunes ${ }^{2}$, Maria Cândida \\ de Almeida Lopes ${ }^{3}$
}

${ }^{1}$ Piracicaba Dental School, State University of Campinas, Piracicaba, Sao Paulo, Brazil.

${ }^{2}$ Department of Morphology, Center for Health Sciences, Federal University of Piauí, Teresina, Piauí, Brazil.

${ }^{3}$ Department of Pathology and Dental Clinics, Federal University of Piauí, Teresina, Piauí, Brazil.

\section{Corresponding Author:}

Marcelo Breno M. Mendes

Faculdade de Odontologia de Piracicaba, Universidade Estadual de Campinas

Av Limeira, 901. Bairro Areião - CEP 13414-903, Piracicaba, Sao Paulo

Brazil

Phone: +55 192106-5708

Email: marcelobreno@yahoo.com.br; marcelobrenocbmf@gmail.com

\begin{abstract}
Objectives: This study evaluated the relationship of the lingual nerve with the adjacent anatomical structures of the mandibular third molar region, influencing the dentist to be aware of the variability of these relationships.

Material and Methods: Samples of 24 human corpse half-heads were selected and divided according with the presence or absence of the mandibular third molars. The lingual nerve (LN) was explored, showing its run from the oblique line until its crossing with the submandibular gland duct. The measurements along the LN and the adjacent anatomical structures were taken at the retromolar, molar and sublingual region with the use of a digital caliper.

Results: The distance from the LN and the third molar socket, which represents the horizontal distance of the lingual plate to the nerve, on average, was $4.4 \mathrm{~mm}$ (SD $2.4 \mathrm{~mm}$ ). The distance from the LN and the lingual alveolar rim, which represents the vertical relationship between the nerve and the lingual alveolar rim of the third molar socket, on average, was $16.8 \mathrm{~mm}$ (SD $5.7 \mathrm{~mm}$ ). The LN has a varied topography that leaves it very vulnerable during any procedure executed in this region. Conclusions: Unless adequate protection of the lingual nerve is acquired by following an adequate surgical technique, the lingual nerve will always be vulnerable to damage during surgical intervention or manipulation in this region.
\end{abstract}

Keywords: lingual nerve; lingual nerve injury; third molar; paresthesia.

Accepted for publication: 27 December 2013

To cite this article:

Mendes MBM, de Carvalho Leite Leal Nunes CM, de Almeida Lopes MC. Anatomical Relationship of Lingual Nerve to the Region of Mandibular Third Molar.

J Oral Maxillofac Res 2013;4(4):e2

URL: http://www.ejomr.org/JOMR/archives/2013/4/e2/v4n4e2ht.pdf

doi: $10.5037 /$ jomr.2013.4402 


\section{INTRODUCTION}

The relationship of the anatomical structures in the retromolar region makes any procedures executed in this region very complex, the extraction of the mandibular third molar being the most frequent surgical intervention accomplished there. Many times, this procedure is executed by professionals who are not specialists in oral and maxillofacial surgery, which puts the integrity of the lingual nerve (LN) at risk.

The LN, one of the mandibular nerve branches, third division of the trigeminal nerve, presents fibres of the chorda tympani nerve, a branch of the facial nerve, responsible for the sensitive innervations of the anterior two thirds of the tongue and for the parasympathetic innervations of the sublingual and submandibular glands [1]. According to Figún [2], the chorda tympani nerve is an extensive communicated branch, between the facial and LNs, which has sensory taste fibres, relating to the anterior two thirds of the tongue and from the palatal vault, and parasympathetic secretor fibres going to the submandibular and sublingual glands. These anastomoses explain the loss of taste in the lesions of the LN. In the infratemporal fossa, the lingual and inferior alveolar nerves are crossed by the maxillary artery, which runs horizontally, around the medial condyle's head, followed by the maxillary vein. The mandibular third molar is situated at the end of the body of the mandible where it is connected with the relatively thin ramus. The buccal alveolar bone in this region is thicker than the lingual. The LN often lies close to the cortical plate. So, there is a high risk of LN damage using the lingual split technique or elevating the third molar flap medially to the distoangular recess []].

Furthermore, injury to the nerve might occur iatrogenically by direct injury caused by the tooth dislocation to the submandibular region during extraction or for excision of the nerve during the removal of a tumor of the submandibular gland, followed by trauma, orthognathic surgery, third molar extraction due to the intubation procedures of general anesthesia, endodontic treatment of the posterior teeth, tooth implants, intraosseous lesions curettage, partial or total resection of the tongue or mandibular and periodontal procedures [4-8] beyond local anesthesia $[9,10]$.

The present study aimed to describe the anatomic relationship of the LN with the nearby structures in the retromolar region and in the third molar socket, disclosing its pathway from the retromolar region until the point that it runs along the floor of the mouth, crossing with the submandibular gland duct.

\section{MATERIAL AND METHODS}

Twenty four human corpse half heads were sagittally dissected. In all cases the third molar had completely erupted and it was not possible to determine the gender, since the samples were detached from the body. The presence or absence of the mandibular third molar was registered. The exploration of the $\mathrm{LN}$ was accomplished through a four centimeter incision in the retromolar region until the point that it adopted a horizontal pathway moving away from the lingual plate, at the point that it crosses with the submandibular duct.

The point at the oblique line in the retromolar region was defined as point $\mathrm{A}$. The central point in the lingual gingival margin that corresponds to the third molar socket was identified as point B. The point at which the submandibular duct intersects the LN in the sublingual region was identified as point $\mathrm{C}$. The proper nerve at the retromolar region was defined as point $\mathrm{D}$. The point of the LN, at the level of the third molar mandibular socket, nearest the lingual cortical and that intersects an imaginary line parallel to the long axis of the socket was defined as point $\mathrm{E}$.

The following measurements were taken: the retromolar region (A) to the point nearest the LN (D); the third molar socket (B) to the $\mathrm{LN}$ point in the retromolar region (D); the distance between the alveolar rim (B) and the point at which the submandibular duct intersects the $\mathrm{LN}$ in the oblique direction $(\mathrm{C})$; the distance from the third molar socket (B) to the $\mathrm{LN}(\mathrm{E})$ in a horizontal direction and vertical direction. The measurements were taken from the most superior aspect of the LN (Figure 1).

\section{Statistical analysis}

All of the measurements were realized by the same examiner through a manual caliper and analyzed by the SPSS 16.0 program, through a descriptive analysis via the measurement of the medium-position and the measure of the standard deviation (SD) variability.

\section{RESULTS}

The mean distance between point $\mathrm{A}$ to point $\mathrm{D}$ was 7.2 $\mathrm{mm}$ (SD $1.7 \mathrm{~mm}$ ). The $\mathrm{B}$ to $\mathrm{D}$ distance, on average, was $9.4 \mathrm{~mm}$ (SD $1.8 \mathrm{~mm}$ ). Point $\mathrm{B}$ to point $\mathrm{C}$ was, on average, $22.6 \mathrm{~mm}$ (SD $6.6 \mathrm{~mm}$ ). The relationship of point $\mathrm{B}$ to point $\mathrm{E}$, in a horizontal direction, which represents the distance of the lingual plate to the nerve was $4.4 \mathrm{~mm}$ (SD $2.4 \mathrm{~mm}$ ), ranging from $11 \mathrm{~mm}$ to 2 $\mathrm{mm}$. The distance between points $\mathrm{B}$ and $\mathrm{E}$, in the vertical direction, which represents the relationship between the nerve and the lingual alveolar rim, 


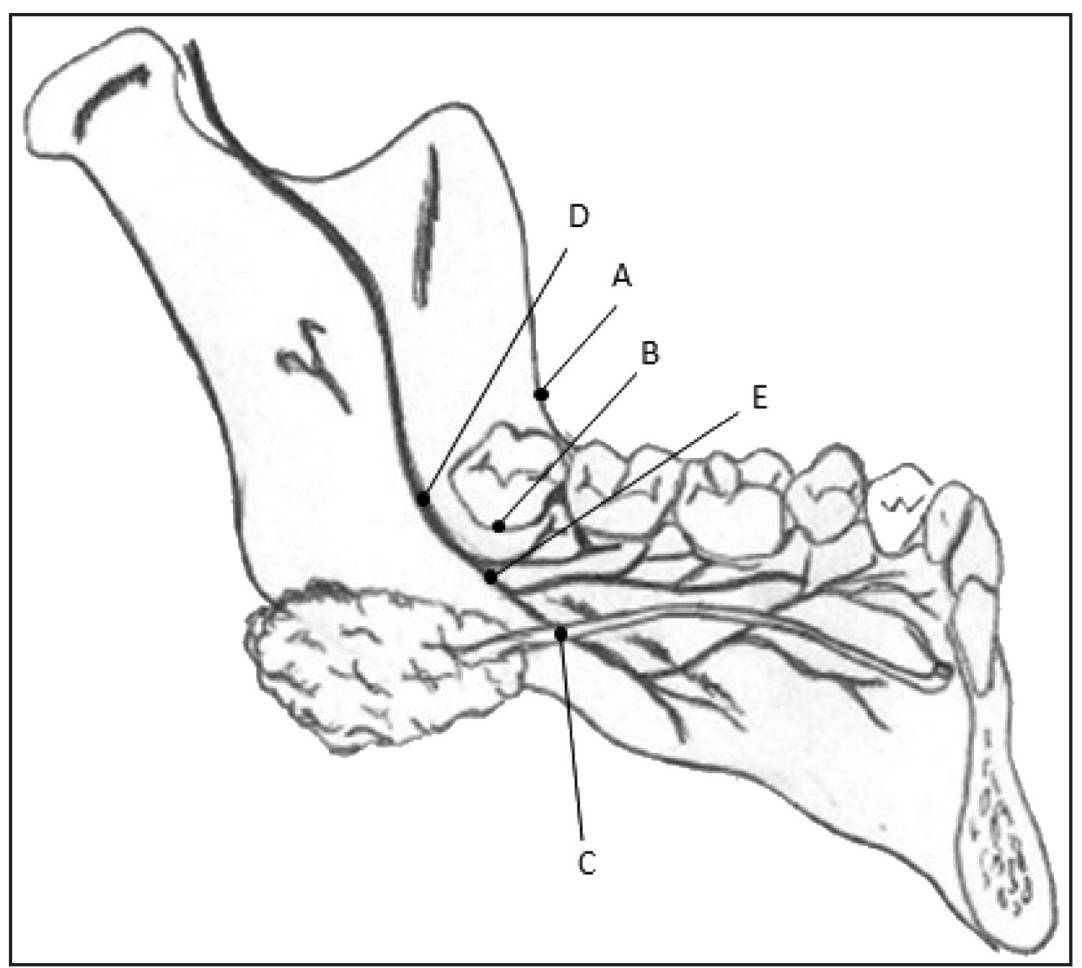

Figure 1. Project representing the reference points adopted for the measures: $A=$ retromolar region; $B=$ third molar socket; $C=$ intersection point between $\mathrm{LN}$ and submandibular duct, $\mathrm{D}=\mathrm{LN}$ at retromolar region and $\mathrm{E}=$ The point of $\mathrm{LN}$, at the level of the third molar mandibular socket, nearest lingual cortical and that intersects an imaginary line paralled to the long axis of the socket.

was $16.8 \mathrm{~mm}$ (SD $5.7 \mathrm{~mm}$ ), ranging from $29 \mathrm{~mm}$ to $12 \mathrm{~mm}$. At the point that the $\mathrm{LN}$ intersects the submandibular duct, there was no constant position relative to the nerve and the duct. In this study, 15 side heads presented the submandibular duct (Warton's duct) and passed over the LN, and in 9 cases, the duct crossed below the nerve. From the 24 parts analyzed in this study, seven presented healthy mandibular third molar teeth, 12 parts also had the inferior second molar, and 3 parts also presented the maxillary third molar.

\section{DISCUSSION}

In this study, the distance between the retromolar region (A) and the $\mathrm{LN}(\mathrm{D})$, in the retromolar region, was $7.2 \mathrm{~mm}$ (SD $1.7 \mathrm{~mm}$ ) and the distance between the $\mathrm{LN}$ (D) in the retromolar region, and the third molar socket (B) was $9.4 \mathrm{~mm}$ (SD $1.8 \mathrm{~mm}$ ) (Figure 1). This distance does not provide security or comfort to the surgeon to accomplish large incision maneuvers and detachment of the nearby tissue, since some cases require extensive detachment, and point A limits the $\mathrm{LN}$ position in this region.

According to the Pell and Gregory classification, this distance tends to be closer in the level 3 position the mandibular third molar in the mandibular ramus in which the nerve runs nearest to the retromolar region, presenting vulnerability during surgical procedures in this region [11]. Pogrel et al. [12] found one case where the nerve passed above the mandibular lingual plate. In this position, the $\mathrm{LN}$ is vulnerable to trauma, may suffer injury during gingival detachment in the retromolar region and is difficult to reach even in procedures that don't involve sharpened instruments in the lingual plate of the mandible [12].

The distance between the alveolar rim, at the level of the third molar region (B), and the sublingual region at the intersection point between the $\mathrm{LN}$ and the submandibular gland duct (C) was found to be $22.6 \mathrm{~mm}$ (SD $6.6 \mathrm{~mm}$ ) (Table 1 and Figure 1), and was located in the premolars region. It is important to observe the relationship between the nerve and the duct of the submandibular gland (Warton's duct), because the position of both structures is not always maintained the same. This relationship is very important during surgical procedures involving the submandibular gland. In this study, in $62.5 \%$ of the cases, the duct passed above the nerve and in $37.5 \%$ the nerve passed below the duct. Hölzle and Wolff [13] investigated the relationship of the LN with the adjacent structures in the atrophic jaws. They found that in most cases the Wartons' duct passed above the $\mathrm{LN}$, and of a total of 34 samples, they found in 4 cases the Warton's duct running deeply in the floor of the mouth, which they did not find with the LN (Figure 2).

With respect to the horizontal distance (BE), $4.4 \mathrm{~mm}$ (SD $2.4 \mathrm{~mm}$ ) was found between the LN 
Table 1. Average and standard deviation by type of measure of the distances between lingual nerve (LN) and the adjacent structures in the inferior third molar region

\begin{tabular}{l|c|c}
\hline \multicolumn{1}{c|}{ Relationship Structures } & $\begin{array}{c}\text { Average } \\
(\mathbf{m m})\end{array}$ & $\begin{array}{c}\text { Standard Deviation } \\
(\mathbf{m m})\end{array}$ \\
\hline Retromolar region and LN (A - D) & 7.2 & 1.7 \\
\hline Third molar socket and LN (B - D) & 9.4 & 1.8 \\
\hline Distance between alveolar (B - C) rim and the sublingual region in the intersection point & 22.6 & 6.6 \\
\hline Distance of the third molar (B - E) socket and the LN in the horizontal direction & 4.4 & 2.4 \\
\hline Distance of the alveolar rim (B - E) of the third molar and the LN in vertical direction & 16.8 & 5.7 \\
\hline
\end{tabular}

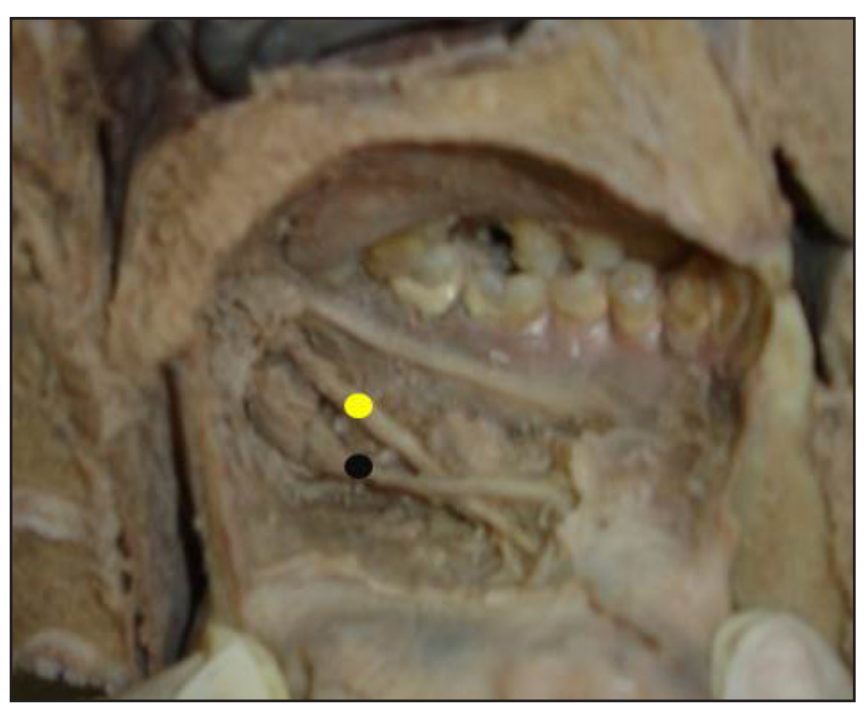

Figure 2. Image showing the intersection point between LN (yellow) and the submandibular gland duct (black).

and the mandibular plate, at the level of the third molar socket (Figure 3 and Table 1). This result was greater than that found by Pogrel et al. [12] $(3.45 \mathrm{~mm}$; SD $1.48 \mathrm{~mm})$, by Behnia et al. [14] $(2.06 \mathrm{~mm}$; SD $1.1 \mathrm{~mm})$ and by Hölzle and Wolff [13] $(0.86 \mathrm{~mm}$; SD $1 \mathrm{~mm})$. Kiesselbach and Chamberlain [15] found a horizontal distance of $0.59 \mathrm{~mm}$ (SD $0.9 \mathrm{~mm}$ ) between the $\mathrm{LN}$ and the mandibular lingual plate. Miloro et al. [16] found this same relationship with $2.53 \mathrm{~mm}$ (SD $1.48 \mathrm{~mm}$ ). These distances are smaller than those found in the present study. This can be justified for the size of our sample, since in the Behnia et al. study [14] it involved 669 LNs in 430 corpses with a maximum of $24 \mathrm{~h}$ post-mortem. Our specimens were conserved by immersion in $10 \%$ formaldehyde, with a time of immersion varying from 2 to 5 years, which might cause changes in the tissue volume of the analyzed parts.

Another fact that might have contributed to the divergence of our result in the horizontal measure was the method used. In the research of Pogrel et al. [12] and in the Hölzle and Wolff [13] studies, the LN was measured taking the retromolar region as a reference, and not the third molar socket, as was done in our study. The measure found in this study highlights

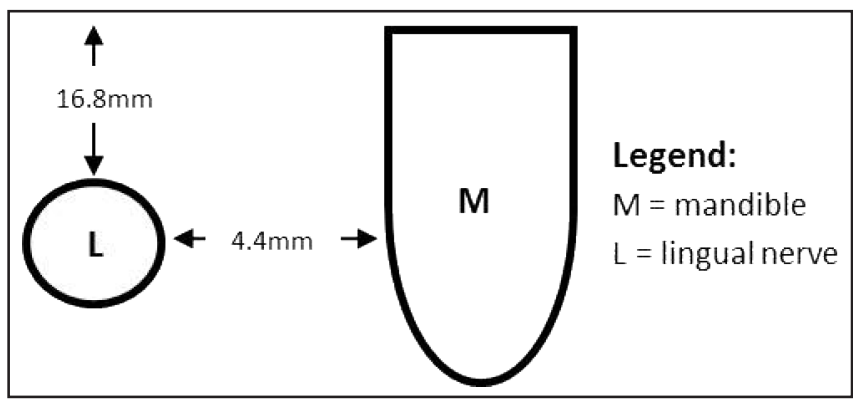

Figure 3. Diagram of the vertical and horizontal relationship between LN and lingual plate of the mandible, measured from the most external surface of the nerve. The vertical average distance found was $16.8 \mathrm{~mm}$ (SD $5.7 \mathrm{~mm}$ ) and the horizontal one was $4.4 \mathrm{~mm}(\mathrm{SD} 2.4 \mathrm{~mm})$.

the relationship between the $\mathrm{LN}$ and the mandibular lingual plate $-4.4 \mathrm{~mm}$, representing great vulnerability to the nerve. During dental sectioning, it is important that the drill does not completely disrupt the entire tooth. This surgical step must be completed by the introduction of a straight extractor and the dental division is achieved by movements of rotation inside the tooth. This is important for nerve protection.

When the vertical relationship between the LN (E) and the mandibular lingual plate in the third molar region (B) was analyzed, a distance of $16.8 \mathrm{~mm}$ (SD $5.7 \mathrm{~mm}$ ) was found (Figure 3 and Table 1). This result contrasts with the data found by Pogrel et al. [12] $(8.32 \mathrm{~mm}$; SD $4.05 \mathrm{~mm})$, by Behnia et al. [14] (3.01 mm; SD $0.42 \mathrm{~mm})$, by Hölzle and Wolff [13] $(7.83 \mathrm{~mm}$; SD $1.65 \mathrm{~mm})$, by Kiesselbach and Chamberlain [15] (2.28 mm; SD $0.9 \mathrm{~mm})$ and Miloro et al. [16] $(2.75 \mathrm{~mm}$; SD $0.97 \mathrm{~mm})$.

Pogrel et al. [12] and Hölzle and Wolff [13] carried out measures with the retromolar region as a reference and not the third molar socket. The study executed by Behnia et al. [14] involved the greatest sample in the literature, totaling 669 nerves. They found that in $14.05 \%$ of the cases the nerve passed above the mandibular lingual plate and in one case it ran in the retromolar region accurately on the mandibular surface. In $85.8 \%$ of the cases, the nerve was in its typical position and in 149 cases $(23.27 \%)$ it was in direct contact with the lingual plate of the jaw in the alveolar process. 
They affirm that there were no difference in the LN position in males and females and no correlation between the LN positions at each side, with both presenting independent topographies $[12,14]$.

Bataineh [17] investigated the sensory impairment of the lingual and inferior alveolar nerves after removal of impacted mandibular third molars under local anesthesia and found $2.6 \%$ of the patients presenting paresthesia in the $\mathrm{LN}$ region, with increased incidence associated with increased lingual flap.

Fielding and Reck [18] registered a case of permanent bilateral anesthesia of the $\mathrm{LN}$ after removal of the third molar and the most probable cause was the anomalous position of the LN. Robinson and Smith [19] defend that avoiding lingual retraction reduces the incidence of temporary and permanent damage. The incidence of damage to the $\mathrm{LN}$ was reduced to $0.2 \%$ when the lingual flap is avoided and when the lingual plate is preserved [20]. Current protocols in the EUA emphasize the increased buccal flap, avoiding involvement of the lingual tissue to reduce the risks of impairment to the LN [21-23].

Pogrel and Goldman [24] proposed the use of a lingual flap retractor. This instrument, with a double-ended shaped to fit the lingual contour of the mandible of the third molar region, would be inserted between the lingual periosteum and the lingual plate of the jaw, providing more space for the surgeon to work, better visibility and lingual flap protection. This technique would be used for procedures of dental sectioning and bone removal in the distal region to the third molar. Using this instrument in only $1.6 \%$ of the cases presented temporary paresthesia and no case of permanent damage.

Many surgeons prefer to use some instruments to perform the nerve protection, as with the Molt $\mathrm{n}^{\circ} 9$ instrument. Nevertheless, there are cases of LN injury by compression, because of its sharp edges and because it did not supply sufficient control during insertion in the depth of the Molt n $n^{\circ} 9[19,25,26]$. Chossegros et al. [27] evaluated the protection of the LN with a periosteum rising (Molt or similar). They concluded that the LN protection, in these cases, is totally unnecessary, which has no advantage for $\mathrm{LN}$ protection.

Many times it is impossible to accomplish the mandibular third molar removal or other procedures involving this same region without manipulating the lingual mucosa, which already enables injury to the nerve, even temporarily. This complication must be discussed with the patient to orientate him at the consultation before surgery $[\underline{28}, \underline{29}]$. Blackburn and Bramley [30] affirmed that the bone must be removed in order to facilitate visualization and the drill must be advanced/directed by the surgeon. In every case the third molar flap should provide adequate visualization of the surgical field [ $\underline{3}$ ]. The LN is not purely injured only in dentistry procedures. There are cases in the literature of damages to the $\mathrm{LN}$ following endotracheal intubation for procedures that do not involve the oral structures [4-8]. In a recent study, the incidence of damage to the LN was higher in mandibular third molar surgeries under general anesthesia (18\%) than 3\% under local anesthesia [31]. The etiology of LN damage associated with general anesthesia is multifactorial: complicated and forced laryngoscope, several attempt of laryngoscope, anterior displacement of the jaw for a long period, compression of the tongue, macroglossia, placing a drain plug in the throat and mandibular retraction [32].

Niemi et al. [33] affirmed that the deterioration of the function of the LN becomes more difficult with tongue control in anterior-posterior movements. This involvement in the voice production might be the result of the motor impairment, suggesting that the damage also results in interference in the proprioceptive answer of the muscular fibres of the tongue. This makes the tongue perform movements with less precision.

Treatment of nerve injuries remains controversial. Repairs with or without grafts done immediately after trauma have better results [34], with progressive worsening when done $3,6,9$ or 12 months after the injury [35]. However, the recovery of the patient is unpredictable. Although there have been several attempts, there is not yet an attendance protocol for these cases. In addition, the long-term outcome of microsurgery is very variable [36]. Maybe, the difficult access and the constant mobility in the surgery area (to eat, to swallow and to speak) can contribute to the low success rate.

\section{CONCLUSIONS}

This study showed a close relationship of the lingual nerve and the mandibular lingual cortical, presenting a distance of $4.4 \mathrm{~mm}$ horizontally and $16.8 \mathrm{~mm}$ vertically. As a result, unless adequate protection of the lingual nerve is acquired by following an adequate surgical technique, the lingual nerve will always be vulnerable to damage during surgical intervention or manipulation in this region.

\section{ACKNOWLEDGMENTS AND DISCLOSURE STATEMENTS}

The author report no conflicts of interest related to this study. 


\section{REFERENCES}

1. Fehrenbach MJ, Herring SW, Thomas P. Illustrated anatomy of the head and neck. 3rd ed. St. Louis, Mo.: Saunders/ Elsevier; 2007. p. 341.

2. Figún ME, Garino RR. Anatomia odontológica funcional e aplicada. 2nd ed. Porto Alegre: Artmed, 2003. p. 532.

3. Juodzbalys G, Daugela P. Mandibular Third Molar Impaction: Review of Literature and a Proposal of a Classification. J Oral Maxillofac Res 2013;4(2):e1. URL: http://www.ejomr.org/JOMR/archives/2013/2/e1/v4n 2e1ht.htm [doi: $10.5037 /$ jomr.2013.4201]

4. James FM. Hyperaesthesia of the tongue. Anaesthesiology 1975;42(3):359. [doi: 10.1097/00000542-197503000-00022]

5. Jones BC. Lingual nerve injury: a complication of intubation. Br J Anaesth. 1971 Jul;43(7):730. [Medline: 5564251]

6. Loughman E. Lingual nerve injury following tracheal intubation. Anaesth Intensive Care. 1983 May;11(2):171. [Medline: 6869781]

7. Peterson LJ, Ellis E, Hupp JR, Tucker MR. Contemporary oral and maxillofacial surgery. 2nd ed. St Louis: MO, Mosby; 1993 Feb. p. 237.

8. Teichner RL. Lingual nerve injury: a complication of orotracheal intubation. Case report. Br J Anaesth. 1971 Apr;43(4):4134. [Medline: 5575191] [doi: 10.1093/bja/43.4.413]

9. Gülicher D, Gerlach KL. Sensory impairment of the lingual and inferior alveolar nerves following removal of impacted mandibular third molars. Int J Oral Maxillofac Surg. 2001 Aug;30(4):306-12. [Medline: 11518353] [doi: 10.1054 /ijom.2001.0057]

10. Harn SD, Durham TM. Incidence of lingual nerve trauma and postinjection complications in conventional mandibular block anesthesia. J Am Dent Assoc. 1990 Oct;121(4):519-23. [Medline: 2212345]

11. Pell GJ, Gregory GT. Impacted mandibular third molars, classification and modified technique for removal. Dent Digest. 1933;39:330-338.

12. Pogrel MA, Renaut A, Schmidt B, Ammar A. The relationship of the lingual nerve to the mandibular third molar region: an anatomic study. J Oral Maxillofac Surg. 1995 Oct;53(10):1178-81. [Medline: 7562172] [doi: 10.1016/0278-2391(95)90630-4]

13. Hölzle FW, Wolff KD. Anatomic position of the lingual nerve in the mandibular third molar region with special consideration of an atrophied mandibular crest: an anatomical study. Int J Oral Maxillofac Surg. 2001 Aug;30(4):333-8. [Medline: 11518358] [doi: 10.1054/ijom.2001.0064]

14. Behnia H, Kheradvar A, Shahrokhi M. An anatomic study of the lingual nerve in the third molar region. J Oral Maxillofac Surg. 2000 Jun;58(6):649-51; discussion 652-3. [Medline: 10847287] [doi: 10.1016/S0278-2391(00)90159-9]

15. Kiesselbach JE, Chamberlain JG. Clinical and anatomic observations on the relationship of the lingual nerve to the mandibular third molar region. J Oral Maxillofac Surg. 1984 Sep;42(9):565-7. [Medline: 6590806] [doi: 10.1016/0278-2391(84)90085-5]

16. Miloro M, Halkias LE, Slone HW, Chakeres DW. Assessment of the lingual nerve in the third molar region using magnetic resonance imaging. J Oral Maxillofac Surg. 1997 Feb;55(2):134-7. [Medline: 9024349] [doi: 10.1016/S0278-2391(97)90228-7]

17. Bataineh AB. Sensory nerve impairment following mandibular third molar surgery. J Oral Maxillofac Surg. 2001 Sep;59(9):1012-7; discussion 1017. Review. [Medline: 11526568] [doi: 10.1053/joms.2001.25827]

18. Fielding AF, Reck SF. Bilateral lingual nerve anesthesia following mandibular third molar extractions. Oral Surg Oral Med Oral Pathol. 1986 Jul;62(1):13-6. [Medline: 3460003] [doi: 10.1016/0030-4220(86)90063-0]

19. Robinson PP, Smith KG. Lingual nerve damage during lower third molar removal: a comparison of two surgical methods. Br Dent J. 1996 Jun 22;180(12):456-61. Review. [Medline: 8703598] [doi: 10.1038/sj.bdj.4809126]

20. Appiah-Anane S, Appiah-Anane MG. Protection of the lingual nerve during operations on the mandibular third molar: a simple method. Br J Oral Maxillofac Surg. 1997 Jun;35(3):170-2. [Medline: 9212292] [doi: 10.1016/S0266-4356(97)90557-X]

21. Alling RD, Alling C. Part 1, Mandibular third molars buccalocclusal approaches. In: Alling CC, Helfrick JF, Alling RD editors. Impacted Teeth. Philadelphia: W.B. Saunders; 1993. p. 150-202.

22. Khanuja A, Powers MP. Surgical management of impacted teeth. In: Fonseca RJ editors. Oral and Maxillofacial Surgery. Vol 1. Philadelphia: PA, Saunders, 2000. p. 259-68.

23. Peterson LJ. Principles of management of impacted teeth. In: Peterson LJ, Indresano AT, Marciani RD editors. Principles of Oral and Maxillofacial Surgery, vol 1. Philadelphia: PA, Lippincott; 1992. p. 103-17.

24. Pogrel MA, Goldman KE. Lingual flap retraction for third molar removal. J Oral Maxillofac Surg. 2004 Sep;62(9):112530. [Medline: 15346365] [doi: 10.1016/j.joms.2004.04.013]

25. Robinson PP, Loescher AR, Smith KG. A prospective, quantitative study on the clinical outcome of lingual nerve repair. Br J Oral Maxillofac Surg. 2000 Aug;38(4):255-63. [Medline: 10922146] [doi: 10.1054/bjom.2000.0463]

26. Rood JP. Permanent damage to inferior alveolar and lingual nerves during the removal of impacted mandibular third molars. Comparison of two methods of bone removal. Br Dent J. 1992 Feb 8;172(3):108-10. [Medline: 1739507] [doi: 10.1038/sj.bdj.4807777] 
27. Chossegros C, Guyot L, Cheynet F, Belloni D, Blanc JL. Is lingual nerve protection necessary for lower third molar germectomy? A prospective study of 300 procedures. Int J Oral Maxillofac Surg. 2002 Dec;31(6):620-4. [Medline: 12521318] [doi: 10.1054/ijom.2002.0236]

28. Collins MRN. Paraesthesia following lower wisdom tooth extraction. J Med Defence Union. 1988:4:41.

29. MacGregor AJ. The Impacted Lower Wisdom Tooth. Oxford: Oxford University Press; 1985.

30. Blackburn CW, Bramley PA. Lingual nerve damage associated with the removal of lower third molars. Br Dent J. 1989 Aug 5;167(3):103-7. [Medline: 2765316] [doi: 10.1038/sj.bdj.4806922]

31. Bruce RA, Frederickson GC, Small GS. Age of patients and morbidity associated with mandibular third molar surgery. J Am Dent Assoc. 1980 Aug;101(2):240-5. [Medline: 6931159]

32. Lang MS, Waite PD. Bilateral lingual nerve injury after laryngoscopy for intubation. J Oral Maxillofac Surg. 2001 Dec;59(12):1497-9. [Medline: 11732044] [doi: 10.1053/joms.2001.28293]

33. Niemi M, Laaksonen JP, Vähätalo K, Tuomainen J, Aaltonen O, Happonen RP. Effects of transitory lingual nerve impairment on speech: an acoustic study of vowel sounds. J Oral Maxillofac Surg. 2002 Jun;60(6):647-52; discussion 653. [Medline: 12022101] [doi: 10.1053/joms.2002.33113]

34. Wiethölter H, Riediger D, Ehrenfeld M, Cornelius CP. [Results of microsurgery of sensory peripheral branches of the mandibular nerve]. Fortschr Kiefer Gesichtschir. 1990;35:128-34. German. [Medline: 2197193]

35. Wolford LM, Stevao EL. Considerations in nerve repair. Proc (Bayl Univ Med Cent). 2003 Apr;16(2):152-6. [PMC free article: 1201001] [Medline: 16278731]

36. Pogrel MA. The results of microneurosurgery of the inferior alveolar and lingual nerve. J Oral Maxillofac Surg. 2002 May;60(5):485-9. [Medline: 11988920] [doi: 10.1053/joms.2002.31841]

\section{To cite this article:}

Mendes MBM, de Carvalho Leite Leal Nunes CM, de Almeida Lopes MC. Anatomical Relationship of Lingual Nerve to the Region of Mandibular Third Molar.

J Oral Maxillofac Res 2013;4(4):e2

URL: http://www.ejomr.org/JOMR/archives/2013/4/e2/v4n4e2ht.pdf

doi: $10.5037 /$ jomr.2013.4402

Copyright (C) Mendes MBM, de Carvalho Leite Leal Nunes CM, de Almeida Lopes MC. Published in the JOURNAL OF ORAL \& MAXILLOFACIAL RESEARCH (http://www.ejomr.org), 1 January 2014.

This is an open-access article, first published in the JOURNAL OF ORAL \& MAXILLOFACIAL RESEARCH, distributed under the terms of the Creative Commons Attribution-Noncommercial-No Derivative Works 3.0 Unported License, which permits unrestricted non-commercial use, distribution, and reproduction in any medium, provided the original work and is properly cited. The copyright, license information and link to the original publication on (http://www.ejomr.org) must be included. 